\title{
Potential of unconventional design methods for expanding compositional solutions for architectural character of buildings
}

\author{
Aleksandr Pleshivtsev ${ }^{1, *}$ \\ ${ }^{1}$ State University of Land Management, 15, Kazakova str., Moscow, 105064, Russia
}

\begin{abstract}
The present paper considers the capabilities of advanced methods for design of architectural objects. The paper gives characteristics of the process of composing as the traditional and most common method for designing architectural structures. The authors assessed the potential of imparting functionality to architectural objects by using both traditional and innovative methods inherent in the art of architecture. Aspects of adaptation of traditional knowledge to the invention of unconventional approaches to coping with problematic situations were analyzed. The main types of unconventional approaches to design, which are oriented to the increase in the number of conceptual solutions for architectural tasks, were considered.
\end{abstract}

\section{Introduction}

All the well-known techniques of architectural design that were formerly applied, are currently used or might be used in some future, do and will reflect the state and potential (materialized in the shape of certain structures and systems) of intellectual and technological development of object-application knowledge, information and experience. The current state of architectural science in most cases allows ensuring the required quality through the use of various methods and techniques aimed at the formation of architectural systems.

The methodology of the priority motivation of artistic visual thinking, displayed through primarily compositional design solutions, reflects the traditional approach to the improvement of quality of an architectural character.

Architectural composition is traditionally considered the main way of solving problems associated with the elaboration of an object as a single and balanced architectural form that reflects a consistent, aesthetic and harmonious combination of certain volumes and spaces, based on the existence of essential and dominant conditions of the environment (for instance, function, climate, structures, urban planning context) [1,2].

Architectural composition is characterized by the presence of the framework law and certain specific categories, from which the main and secondary are distinguished (for example: spatial structure, harmony, proportion, scale). These categories characterize the

\footnotetext{
*Corresponding author: doptaganka@yandex.ru
} 
main features and specifics associated with working out and functioning of an architectural structure (Fig. 1).

To date, the theory of architectural composition is characterized by the presence of numerous and diverse means and methods of creating a spatial structure that is the main factor ensuring the unity of functional content and shape of an architectural object.

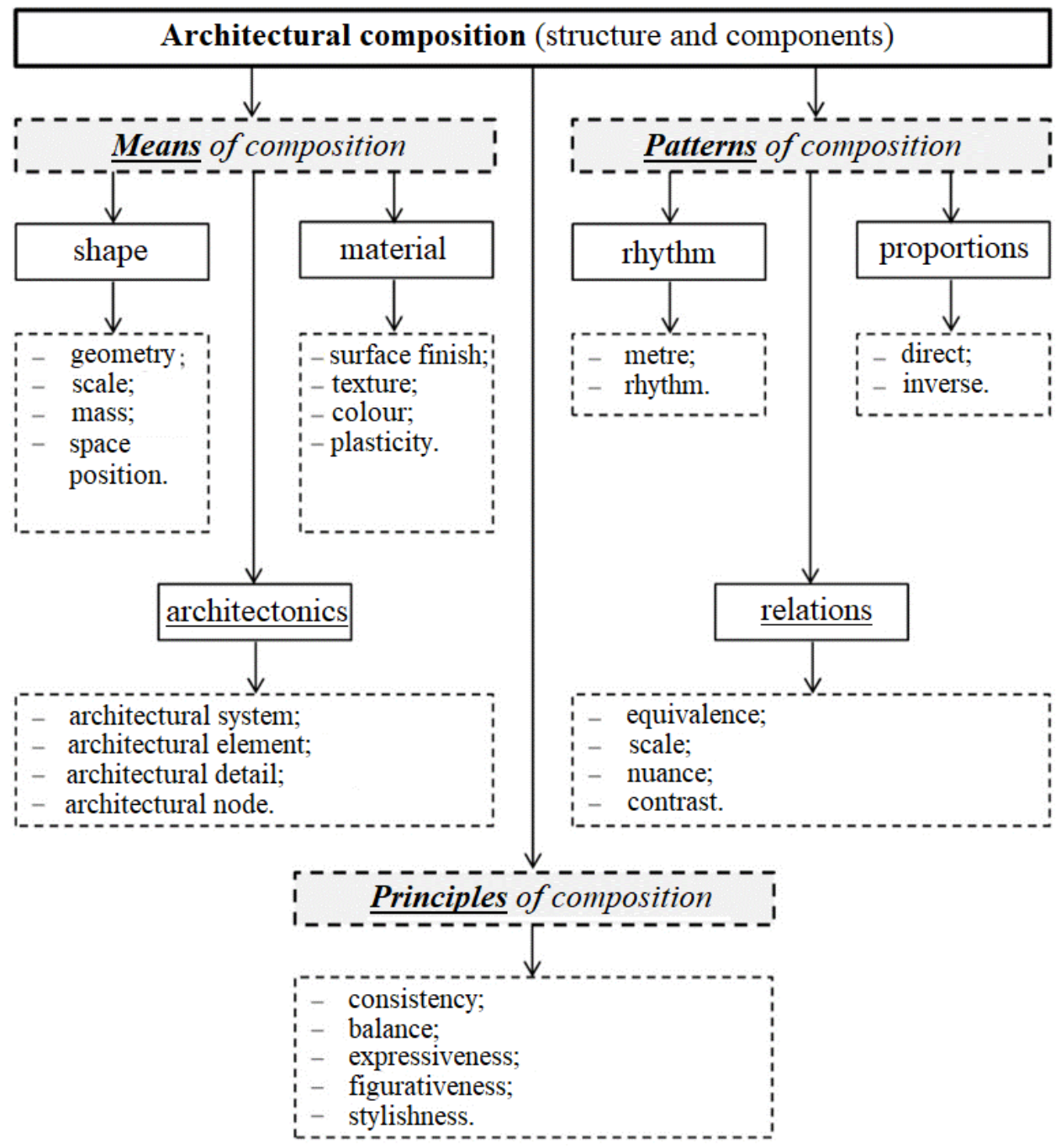

Fig. 1. Structure and components of architectural composition's categories.

Conditions and capabilities of sound, reasonable and effective use of tools and techniques of architectural composition traditionally characterize the level of creative potential and attainments of experts (architects, designers) in the discipline under consideration, indicators of functionality of architectural objects $[3,4]$.

Tools and techniques of composition should be considered as carriers of certain meaningfulness that while interacting with each other during the process of design finally establish quality indicators and properties of an architectural object. 


\section{Results}

One of the main features of modern architectural activity is the use of not only traditional, but also alternative (unconventional) methods of architectonic representation and practical implementation of architectural objects.

Historical experience, knowledge and traditions become the necessary basis that contributes to the formation of unconventional architectural systems, which are worked out primarily for such situations that previously did not get an appropriate solution or did not even consider the very possibility of developing and implementing such a solution. Modern environment of architectural creativity is characterized by continuous grow of functionality standards, improvement of specifics of ensuring the parameters of operating an architectural space, complication of conditions of organization and the effectiveness of the interaction between construction products and the surrounding space.

The complication of conditions for creating advanced and promising architectural objects contributes to the use of scientific and technical (technological) capacity for search, comprehension, integration and recombination of both new and traditional knowledge in innovative solutions to problematic situations pertinent to architectural creativity.

Figure 2 shows a block diagram of the implementation of traditional methods in the process of working out an unconventional solution to a design problem.

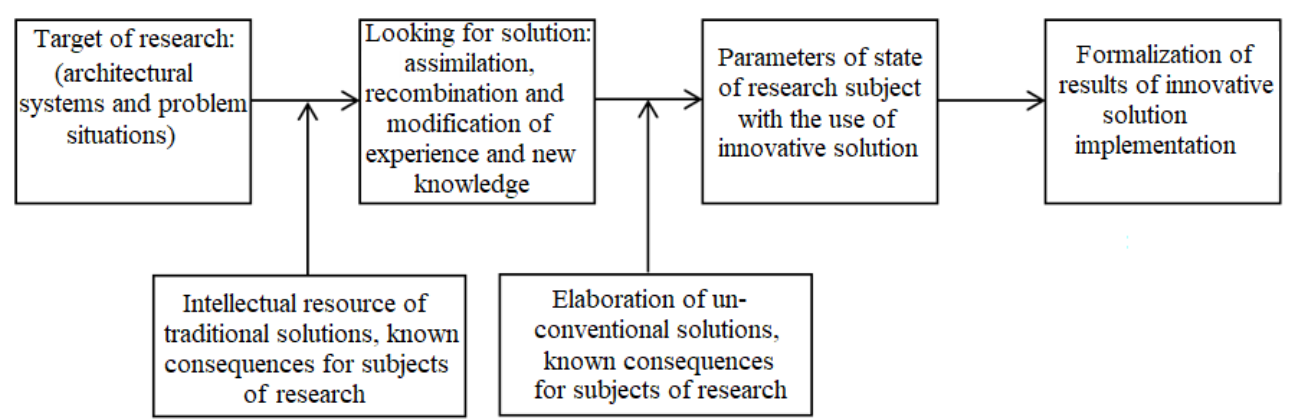

Fig. 2. Block diagram of the process of solving a problem that involves traditional knowledge in elaboration of unconventional problem-solving technique.

Either evolutionary or revolutionary increase in requirements for the functionality of architectural objects may be considered a pivotal factor stimulating the development of an intellectual resource that is capable of identifying the competitiveness of material objects with the use of the necessary (traditional or unconventional) design techniques.

Development and application of unconventional methods of architectural design are consistent with the implicit advancing of architectural knowledge, growing of technical and technological capabilities, which depend not only on research direction, but also on the ability to control the development of knowledge when looking for solutions and elaborating them $[5,6]$.

Capabilities of unconventional methods and principles of designing architectural objects and conditions for their use are distinguished by close connection to the results of scientific and technological progress in the following fields: building materials science, safety systems and ensuring life processes. They are also characterized by improvement of organizational and technological methods and tools of providing construction production, elaboration of new conceptual means and techniques of architectural design. 


\section{Discussion}

The scenario approach focuses on the use of either individual or collective abilities to perceive informational psychophysiological, artistic and aesthetic features (visual quality) of architectural objects. The scenario method of arranging architectural space implies such application of artistic and aesthetic specifics of compositional solutions in space and time, that will provide a targeted formation and "programming" of visual impression made by an architectural character or the entire environment, which might be compared to the versatile and vivid impression made by a piece of art (dramatic performance, concert, movie) [7,8].

Cinematic techniques for applied for making visual images of architectural space establish the phenomenological interpretation of perception of the surroundings or features of their presentation, which affirm the paradigm that there is a plethora of manifestations of each material object belonging to a surrounding space. Common character of cinematic and architectural techniques manifests itself in the following aspects: communicational, semiotic, media, psychological, philosophical.

Table 1 gives a comparative analysis of the common attributes peculiar to architectural and cinematographic techniques.

Table 1. Characteristic of attributes that are common to both architecture and cinema (as art forms).

\begin{tabular}{|c|l|lr|}
\hline \multirow{2}{*}{ Attribute } & \multicolumn{3}{|c|}{ Art form } \\
\cline { 2 - 5 } cinema & \multicolumn{1}{|c|}{ architecture } \\
\hline Style classification & film genre & architectural style \\
\hline $\begin{array}{c}\text { Differential } \\
\text { quality }\end{array}$ & $\begin{array}{l}\text { Art (independent) films/ } \\
\text { mass films (series) }\end{array}$ & $\begin{array}{l}\text { Unique facilities/ standardized } \\
\text { buildings }\end{array}$ \\
\hline $\begin{array}{c}\text { Functional area } \\
\text { Way to express } \\
\text { aesthetic qualities }\end{array}$ & $\begin{array}{l}\text { Timenfiction and space, componential } \\
\text { aspect of image }\end{array}$ & $\begin{array}{l}\text { Material objects } \\
\text { facilities) }\end{array}$ & $\begin{array}{l}\text { Time and space, componential aspect } \\
\text { of image }\end{array}$ \\
\hline $\begin{array}{c}\text { Sources of } \\
\text { qualitative growth }\end{array}$ & $\begin{array}{l}\text { Technologies, materials, artistic } \\
\text { methods }\end{array}$ & $\begin{array}{l}\text { Technologies, materials, design } \\
\text { methods }\end{array}$ \\
\hline $\begin{array}{c}\text { Information } \\
\text { format }\end{array}$ & $\begin{array}{l}\text { Visual perceiving of objective- } \\
\text { spatial environment (sequence) }\end{array}$ & $\begin{array}{l}\text { Visual perceiving of architectural } \\
\text { space (complexes) }\end{array}$ \\
\hline
\end{tabular}

The scenario approach may be considered as an alternative to the typical or singlevariant solution of compositional problems, especially for design situations involving the uncertainty of states associated with conceptual psychological and physiological aspects of human behavior in an artificial (organized) environment. The use of scenario practice for the organization of external and internal architectural space builds a prototype of cultural and conceptual forms of human communication with the natural (surrounding, landscape) and artificial environment, using artistic and imaginative concepts of form making [4,9].

Scenario techniques for architectural space arrangement and visual presentation cover all aspects of composition. These processes are associated with functional characteristics, spatiotemporal characteristics of a composition and features of an architectural image. Revealing the content of processes associated with motion and subjective perception of features of presentation of objects belonging to architectural environment becomes the basis of scenario practice for the purposeful design of the spatial-object environment.

Various technological innovations (primarily in the field of 3D design and visual transformation of space) have a profound impact on the essence and methods of designing architectural characters. The result is an orientation towards new indicators that are not peculiar to traditional design techniques (primarily architectural ones): visuality, dynamic perception, speed - as integral aspects of an architectural character. Artificial intelligence, which is focused on working out special virtual reality, is already considered one of 
possible directions for the development of elaboration methods for an architectural composition $[10,11]$.

The virtual image becomes significant for perception, it becomes full of a plethora of semantic shades and exists in consciousness to the extent that it is interpreted and offered to a subject of representation for understanding. Thus, the only reference to the thingness of the image is the subjective consciousness. Application of principles of the formation of virtual images in order to display features of architectural characters is characterized by the professional use of technical means combined with the spatiotemporal (compositional) principles of design $[12,13]$.

The concept of virtual representation of an artistic image is based on the idea of virtual splitting up of available space through certain representations of shapes. Shapes can be permanent or temporary. They are to be identified by human consciousness and serve as boundaries between the physical and virtual environment (Figure 3).
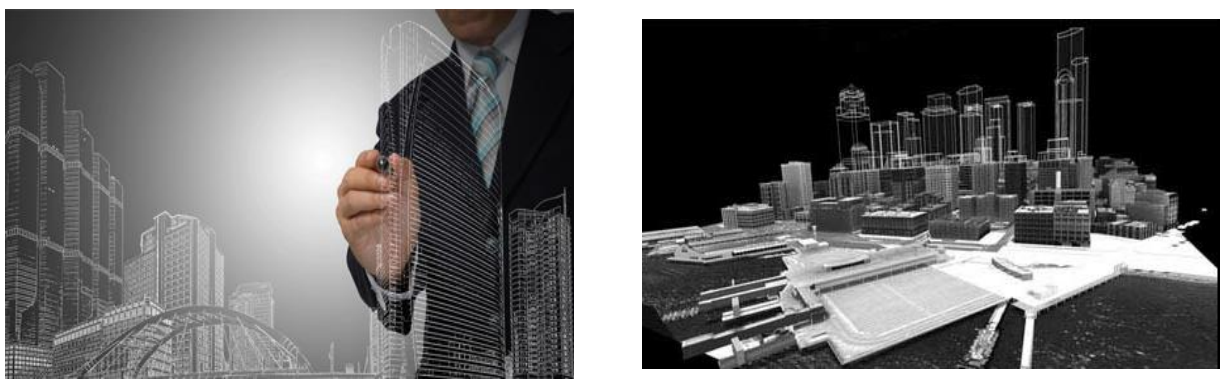

Fig. 3. Techniques and ways of forming a virtual architectural space.

As going further, the concept of displaying the complexity of systemic organization of functional, constructive and artistic components of a composition of an architectural character tends more to the nonlinear logic of computer (artificial) intelligence, which allows analyzing, predicting and modeling the behavior of multifactorial and highly complex systemic (structural) formations of architectural space.

\section{Conclusion}

Advanced modern ideas about architectural activity as a way of integrating imagination (creative design) into objective reality push consciousness to a new level of quality and create fundamentally new approaches to the process of organizing architectural space.

Application of unconventional techniques and principles for design of architectural objects seems a modern, innovative and competitive way (in relation to the mastered and common traditional solutions) of arranging architectural space.

The reasonability and rational scope of application are determined in accordance with the holistic, scientifically grounded doctrine, as well as with a general concept and particular principles of making architectural objects functional.

\section{References}

1. I.A. Azizyan, I.A. Dobritsyna, G.S. Lebedeva, The theory composition as the poetics of architecture (Progress-traditsiya, M., 2002)

2. R. Krier, Architectural composition (Rizzoli, Rome, 1988)

3. A.A. Sardarov, Arkhitektura i stroitel'stvo 4(222), 12-16 (2011) 
4. P.S. Kapustin, Development of ideas about the design object in the processes of architectural thinking. The master's thesis author's abstract on competition of degree of a Cand. Archit. (Voronezh, 1999)

5. A.A. Pleshivtsev, Compositional techniques in architecture (history, theory, workshop) (Vuzovskoye obrazovaniye, Saratov, 2017)

6. S.S. Zhuykov, Trends in the formation of a new global style in architecture. The master's thesis author's abstract on competition degree of a Cand. Archit. (Yekaterinburg, 2018)

7. A.V. Krasheninnikov, Architecture and Modern Information Technologies 4(41), 242256 (2017)

8. A.L. Titov, Organization of the architectural environment and human behavior. The master's thesis author's abstract on competition of degree of a Cand. Archit. (Yekaterinburg, 2004)

9. M.V. Dutsev, The concept of artistic integration in the modern architecture. The master's thesis author's abstract on competition of degree of a Doct. Archit. (Nizhniy Novgorod, 2014)

10. The Evolution of Visual Representation in Architecture (and How It Will Continue to Change) (2020) https://www.archdaily.com/tag/virtual-reality

11. J. Bailenson, Experience on Demand: What Virtual Reality Is, How It Works, and What It Can Do (W.W. Norton \& Company, New York, 2018)

12. M.V. Puchkov, Architecture in the era of information technology (Arkhitekton, Yekaterinburg, 2006)

13. L.V. Savel'yeva, Visual illusions in architectural composition. The master's thesis author's abstract on competition of degree of a Cand. Archit. (M., 2016) 